\title{
Brunello Ceccanti
}

Published online: 23 February 2017

(C) Springer-Verlag Berlin Heidelberg 2017

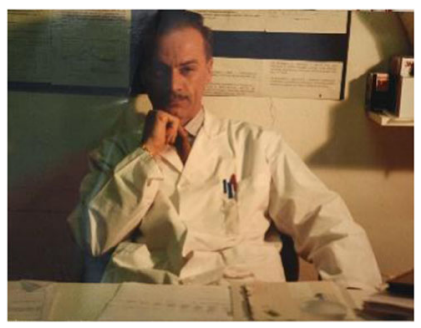

Ceccanti, a world renowned soil enzymologist, died in June 2016. He was born in Peccioli, Pisa, Italy, where he got his degree in Chemistry. He was appointed to CNR, Institute for Soil Chemistry in Pisa, where he was a distinguished soil scientist and retired in December 2010.

Research by Brunello Ceccanti has given fundamental contribution to better understanding of stability and function of extracellular enzyme activities in soil and meaning of soil microbial activity also in relation to soil quality. His laboratory attracted many scientists from all over the world. He collaborated with renowned scientists like Ladd, Speir, and TrasarCepeda. He had a good publication record.

He always tried to make the work easy and stayed with all the scientists who went through his laboratory. He knew how to transmit his knowledge and scientific ideas with enthusiasm and humanity. It is for these reasons that we want to remember not only the scientist but also the colleague and friend who is loved by all those who knew him. 